WellBeing International

WBI Studies Repository

1985

\title{
The Definition, Current Knowledge and Implementation of Welfare for Farm Animals--A Personal View
}

Ron Kilgour

Ruakura Animal Research Station

Follow this and additional works at: https://www.wellbeingintlstudiesrepository.org/acwp_faafp

Part of the Agribusiness Commons, Animal Studies Commons, and the Business Law, Public Responsibility, and Ethics Commons

\section{Recommended Citation}

Kilgour, R. (1985). The definition, current knowledge and implementation of welfare for farm animals-a personal view. In M.W. Fox \& L.D. Mickley (Eds.), Advances in animal welfare science 1985/86 (pp. 31-46). Washington, DC: The Humane Society of the United States.

This material is brought to you for free and open access by WellBeing International. It has been accepted for inclusion by an authorized administrator of the WBI Studies Repository. For more information, please contact wbisr-info@wellbeingintl.org.

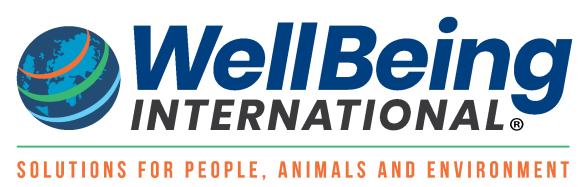




\section{THE DEFINITION, CURRENT KNOWLEDGE AND IMPLEMENTATION OF WELFARE FOR FARM ANIMALS-A PERSONAL VIEW*}

\section{Ron Kilgour}

Ruakura Animal Research Station

Private Bag, Hamilton

New Zealand

\section{Overview}

Being humane to farm animals (welfare) must include (1) having a sound knowledge of their normal and anomalous behavior responses in a farm context and heeding this in a practical way and (2) adopting handling procedures which elicit minimal distress in the species concerned. Building up an ethogram of predictable responses and recording the patterns of behavior during key events, mating, birth, and care of the young are essential. There are still gaps in the recorded ethograms of farm animals. Objective measurements of distress, including an index of its seriousness, are also a priority.

The results from animal preference tests can provide some answers on which to base practical husbandry in the areas of housing design, optimal temperatures, the need for companions, factors which elicit aggression, acceptable feeds, and species' sensory capacities. Handling preference tests could also be undertaken. Overcoming inertia is a problem for both the owners and the animals if changes are to be made within established systems of production.

Gross cruelty can be countered by legislation, but the motivation for ongoing good welfare of farmed animals must come from within the workers/owners on the site. Trying to force it by legislation may be counter-productive. A five-point program for promoting practical animal welfare is outlined.

*Original prepared for CENSHARE seminar on "Behaviour and Welfare of Farm Animals," Minnesota, 1983. 


\section{Introduction}

At times in history, the question of man's use, or exploitation of animals, has been raised for general consideration and this decade appears to be one of these times. It could be beneficial both for husbandry and for animals in farming systems; or it could lead to claim and counter-claim, such that the only loser will be the powerless one in the system, viz. the domestic animal. Since man emerged from hunting, and domesticated plants and animals, some exploitation of both has been practiced to the benefit of civilization. The wide gene pool for some of the basic food plants on which man depends has been whittled away in recent decades. This is also true of farm animal breeds, though a recent renewed interest in rare breeds has in some degree reversed this trend.

The current debate, on welfare matters, involves a reexamination of the "domestic contract" between man and farm animals, pets, fur producers, meat producers, traction animals, and those used for entertainment. The task of this paper is to set some of the guidelines, define some of the terms, so the debate can be creative and lead to some further clarity on the nature, present status, and responsibilities held by each party to the contract: welfarist, husbandman, consumer, scientist, and animal.

\section{Definitions}

\section{Domestication}

Spurway (1955) stated clearly that a domestic animal is "one which as a dead or alive object is accepted as having an economic function as a source of raw material and/or labor for man." The "social function" of pets and animals used for entertainment or sport should be added to this definition. Such animals will have their slaughter, castration, reproduction, feed, and working tasks organized to some degree by humans. The space in which they live, as well as group size, will be dictated by humans. Sossinka (1982) refers to domestication as the most extensive biological "experiment" ever undertaken by human beings, covering many centuries and still in process. A clear distinction is drawn between "domestication"-a process and a "domesticated animal"- the result or state. Martin (1973) provides an alternative definition of domestication as "adaptation to captivity via population genetic mechanisms in which natural selection is largely replaced by artificial selection." Whatever the definition adopted, mankind has invested in a domestic farm animal for some return (Kilgour 1980).

Questions about welfare come after the acceptance that domestication is permissible and will continue - that domestic animals have a place in 
current society. Challenging the right of humans to domesticate a plant or animal is quite another issue.

\section{Humane care}

Mankind exerts control, therefore, mankind must exercise responsible stewardship over domestic animals. Whereas the domesticated jungle fowl or village pig still had a remote chance of escape and return to the "wild" life-style, modern intensively-housed animals have lost this opportunity completely. They must either adapt, show ill thrift as they try to cope, or die. As the degree of control on animals continues to intensify, so we are challenged with the question, "are we being responsible and just in the way we husband and handle animals?"

A number of definitions of animal welfare have been proposed. For example, Hughes (1976) suggested that "welfare is a state of complete mental and physical health in which an animal is in harmony with its environment." He proposed that an animal should be studied in an environment assumed to be ideal, for comparison with animals in their present intensive farming habitat.

If an attempt is made to apply such a definition to people, few would agree in practice on what constitutes "complete" mental health. Many people who regard their welfare as quite adequate may live with ailments, injuries, or physical disabilities brought on by age, which would be at considerable variance with "complete" physical health. Talking to farmers about "complete" mental health in animals is not very helpful. Even welfare as a term has a paternalistic overtone. The term "humane" is more appropriate.

In being "humane" to animals (Kilgour 1978), we must care for and handle them in a manner which causes them the least amount of distress. This can only be done when we fully understand the behavior of the species and their species-specific requirements. This operational definition of welfare links two fundamental areas of study, stress and behavior (Kilgour 1983). The objective assessment of an animal's behavioral repertoire and some key species' requirements is possible though often we lack the will and resources to systematically document their ethograms fully. Modern assays and sampling devices allow some estimates to be made of the distress of an animal during housing or handling, either by monitoring heart or breathing rates, or hormone levels in the blood.

To assist farmers directly involved with domestic animals, we need to frame up more practical questions like: Are the animals behaving normally? Are they producing normally? Are they free from injury and disease? Are the animals housed and handled without undue distress and in accordance with their species' responses and requirements? If the farming systems met these criteria, it is likely that minimum welfare would be satisfied, though the systems might still be improved. If minimum 
welfare is not met, then is the system able to be changed to satisfy the criteria? Has the system to be abandoned and if so, what are the appropriate and viable alternatives? Hens will have to live in cages until a real alternative is provided for them (Wegner 1983). It is pointless returning to a deep litter system with all its inadequacies for the laying hen.

\section{The "Welfare" Debate}

\section{Parties to the current welfare debate}

There are five broad viewpoints in the current "welfare debate" (Kilgour 1980).

\section{Welfarists}

Some people are mildly opposed while others strongly reject many or all forms of intensive husbandry and housing of animals. Some have made a balanced study of modern farming methods and have constructive comments to offer. Others use highly emotive claims which may well be counter-productive as farm owners reject out of hand all such suggestions whether helpful or ridiculous.

\section{Owners and farmers}

These are the people who have elected to gain a livelihood from farming animals. As units became larger, the proportion of the population directly involved in animal industries has declined. Farmers have greatly reduced political influence and may be subjected to strong economic pressures by the rest of society. They can easily get locked into agribusiness.

\section{The public-consumer}

In general, interest in welfare is minimal unless the media draws key issues to the public's attention. On occasions the media provides little background on which to make an informed decision, so the general public tend to remain bewildered spectators. At times, there is resistance to paying more for food even though this might arise as a consequence of improved welfare. Public education campaigns have been promoted by both welfare groups and animal producer boards in some countries. School educational packets for teachers are now available.

\section{Research workers}

These people are commissioned among other things to explore the behavior patterns of domestic animals, their nutritional requirements, inoculation programs and general health, housing designs, and the external stimuli which lead to certain emergency reactions or panic in the stock. In theory, researchers are a disinterested group but they will have their own views as members of the public. 


\section{The animals}

While the debate goes on and more data are collected, the animals still have to live within current systems. Their well-being could improve if husbandry and housing systems are designed to suit their needs more accurately. They may be at risk if ill-informed people force change on the farming industry for change's sake, or corners are cut because of costs. Animals can also be tested to gather more information about their preferences and behavior responses (Klopfer et al. 1981; Kilgour et al. 1984).

\section{The motivation for good welfare}

In a recent review of livestock behavior, Kilgour and Dalton (1984) summarized the source of motivation and welfare, "good farm animal welfare grows from the concerned and informed farmer's response. Legislation will do little to change human behavior or affect human motives. Laws are needed to cover cases of gross cruelty, but codes of practice are more helpful guidelines to improve and suggest ways in which the welfare of livestock can be improved. The husbandman must finally be responsible for the animals in the system and their management, as the terms of the 'domestic contract' are upheld. Codes will be the guide."

Much of the pressure for welfare today comes from people in the ever-growing urban centers who may have little practical experience with rural problems. The divorce of understanding between town and country is an issue facing many developed countries at this time. As the media and the legislature are largely urban-based, the urban welfare lobby's power will continue to grow. Unless animal farming systems are changed with care, the welfare of the animals at present in the system will be at very great risk. To this end, encouraging a farmer's pride may in the long run attain more responsible actions than constant harping criticism.

Improved welfare (animal housing, etc.) costs money. An individual farmer with a concern for welfare could place him or herself at an economic disadvantage compared with others without such interest. When animal products cross national boundaries, countries with higher cost structures resulting from new welfare laws may undermine any former export market advantage.

\section{The nature of the debate}

Lindgren (1976), when discussing the conflict between technical advances and ethics in animal production, attempts to state the nature of the issues largely from the point of view of the farming industry. $\mathrm{He}$ summarizes the debate as follows.

Most objections to modern animal production systems focus on several factors: 
A. Cruelty. This is stated to be affected by the following:

i. Confinement with animal deprived of adequate space, sunlight, pasture, etc.

ii. Automation when animals are dealt with by machines and/or may be deprived of companionship, etc.

iii. Rough handling during transportation and slaughter or mutilation such as castration, beak trimming, etc.

iv. Excessive pressures for high yields.

B. Impairment of quality of the products. Objections are often raised about too much processing, medication in the food, or the use of growth promotants.

C. Impairment of animal health. As production systems change so do the associated disease syndromes. Larger units also present greater risks of disease outbreak.

D. Environmental pollution. This can be at several levels:

i. Micro-level objections as animals increase their resistance to drugs.

ii. Macro-level objections to the pollution of the surrounding areas by smell and wastes, and

iii. human mental pollution which may arise from humans treating animals purely as industrial raw materials.

In the discussion, Lindgren (1976) suggested that the factors related to "cruelty" are probably over-rated, but that genuine objections can be raised on matters of product quality and animal health as long as people keep to facts and not resort to opinions. He classified objectors to large-scale animal production as: (1) Primary critics who include sincere people who support the welfare cause and who have sound reasons for their opinions, or (2) Secondary critics who use the issue for political, media, or radical objectives. In summary, Lindgren suggests: (a) that criticism must always be heard, (b) that public education must be continued and (c) that some international standards of sound management covering matters such as feed, wastes, and welfare should be established.

\section{What farm animals are at greatest welfare risk?}

It is not appropriate to talk abstractly about "welfare." The nature of the species which is at the center of attention is vastly more important.

A proper consideration of the welfare of animals in the system will include: (1) the nature of the species, what their normal and abnormal responses are, the unique features of their life-style which need to be 
provided for and (2) the ways they can be handled such that they are least distressed by each operation.

Each species is unique and its responses have been shaped by changing conditions during its evolutionary past. Kilgour and Dalton (1984) have provided interim behavior definitions for each of the farmed domestic animals, highlighting what they consider to be the unique attributes of each. In this paper two species, the horse and the sheep, will be used to provide examples of the way points (1) and (2) above should be precursors to welfare considerations.

What is a horse? Firstly, a horse is a large animal. It can be dangerous or difficult to handle. The highest number of farm animal injuries to people come from horses (Kilgour and Houston 1979). Once riders have been hurt they may start to fear and even mishandle horses. Despite current knowledge about their size and the associated dangers, small children are still expected to work with horses! Secondly, horses are non-ruminants which have to eat for many hours, especially when pasture is scarce, to meet their requirements. Feral horses inhabit the drier rangelands.

Thirdly, in feral conditions, horses range over large tracts of country. On their daily movement to water they may cover distances of up to sixteen kilometers and their home range areas may reach a thousand hectares. Horses are an energetic species and appear to delight in exercise.

Fourthly, they are social animals and associate in groups, bands, or harems. Most usually this is made up of a stallion with one or more mares and the offspring. The rest of the males remain solitary or associate in bachelor groups. They develop strong social bonds, interact by grooming, or fight using bites or kicks when aggressive. The stallion protects his harem from the approaches of other bands and he may be able to gather up additional members.

Fifthly, to aid their social associations, horses show a range of communication patterns which include: (1) vocal calls. At least seven of these are used for short- and long-range contact and some of them carry over long distances; (2) body postures with movements of ear, tail, mouth, and head which indicate mood or social status at close quarters; (3) odors often attached to dunging rituals which provide information for the traveling bands of horses and mark the trails regularly used. Odors have a function in keeping bands intact and apart from each other.

The sensory capacities of horses are well developed. They have a good sense of touch, smell, hearing, and can see well at distances though they have limited binocular vision immediately in front of the head. They escape predators by flight and should they be attacked, they kick or buck in defense.

Sixthly, as mating is done within a harem structure, the stallions have little problem detecting estrus in the mares. The mares show a 
wide variety in their expression of estrus with little synchrony among females - a pattern which serves a harem life-style very well, but which is rather difficult to deal with on farms.

Finally, mares tend to foal at night when it is quiet. The bond between dam and offspring is made quite quickly. The young are precocious and on their feet, staying with the traveling mare within a few hours of birth. They suckle several times an hour and generally "follow" the dam. The dam protects the foal from the interference of other horses and teaches it much of her own behavior responses while it is following, including good and bad habits.

Is current farm or stable practice in line with the behavioral responses and needs of horses as presently understood? (a) Their keenness for exercise every day may not always be met. Stalled horses get little chance for movement and some of the "vices" which commonly appear may be related to the need to be active. Regular riding will be welcomed by horses and treadmills or excercise machines are used in some stables to provide for these needs. (b) Regular social interactions with other horses may not be provided, especially for the mares, which would be association with others in a harem group. The difficulty of detecting mares in estrus when isolated and a number of other on-farm problems may relate to the diminished opportunities for social interactions in the farm system. In stalls, a strong focus on the responses of other horses may mean that "vices" will be copied by others. (c) Horses spend many hours grazing. What happens in the idle time which is artificially created when horses, given their rations twice a day, are able to eat them within a short space of time? A major adjustment must be made by the horse and the occurrence of anomalous behavior (vices) often become part of the horses' adjustment. (d) Foaling at night. As stud animals become more and more valuable, people want to be present at the birth. This may inhibit the normally relaxed parturition of the mare. Sometimes horses are required to foal in stalls which are too cramped. In these ways, the husbandry systems imposed may be to the detriment of foaling. (e) Man rides a horse by getting onto its back. Before a horse is trained this can produce a response similar to that when a horse is sprung upon by a predator, e.g., a mountain lion, and much bucking results.

The best modes of handling a horse, and the critical time in a foal's development when training should begin need study. In many farm species, handling begins shortly after birth. I have heard welfare objections to foster rearing in species like calves as it "may deprive them of the mother love they get in nature" (Brownlee 1950). However, if handling is left until later in life, "horse-breaking" procedures may be required. Astute observers and horse handlers like Jeffreys in Australia or Ray Hunt in the USA make use of the knowledge of horse flight distance, and correct species approach patterns, to be able to touch, harness, and 
ride horses within minutes of contact without the great struggle of "breaking" horses. Regular handling, gentling, a proper approach, adequate rewards during training are all important for "humane" handling without distress.

What is a sheep? Firstly, a sheep (Kilgour 1976) is a relatively defenseless animal. They gain safety in numbers. Modern day sheep are polled and apart from turning to face or charge a canine predator, and stamping their feet, they have little protection against them. Sheep flock. In fact, most typical species' responses will only be found in groups of three to four sheep or more. Tests of dogs at trials for their ability to work sheep, use three sheep as they tend to split up and make herding a most difficult task for the dog. My rule of thumb is simple, "Four sheep make a sheep." Sheep are also very vigilant and have good vision. They keep in visual contact with other sheep in their group and can flock together quickly should the need arise.

Sheep can be caught by using the blind spot behind the body when they have their heads up, but while they are grazing they can see all about.

Sheep tend to run up hill where they can see their surroundings and they camp at nights on more elevated points.

Sheep grow wool and though this insulates and protects them in cool habitats, it also makes them rather unaware of the cold at key times like lambing. There is little evidence that sheep seek shelter for lambing and under adverse conditions lamb mortality can be high. Pre-lamb shearing however will assist a sheep in making the best use of shelter, and as a result lamb mortality can be reduced where shelter is provided (Lynch et al. 1980). Sheep are open area grazers. They do not reach up and browse like goats nor push through undergrowth as their wool could get tangled. They graze in bouts preferring to take their requirements in less than ten hours a day. They are ruminants. Much of their water is gained from the dew on leaves of plants, though lactating ewes will need extra water. In semi-arid conditions, particularly where the vegetation has a high salt content, the distances sheep walk while grazing will relate to their need to return to watering points (Squires 1981).

Sheep are seasonal breeders in temperate regions, breeding in the autumn or fall. When the rams move into the ewe flocks, they appear to trigger the onset of estrus and help synchronize the ewes. A waxy material in the fleece of the ram is responsible for this "ram effect" (Knight and Lynch 1980). As rams move among the ewes sniff-hunting to find the ones in estrus, they need to be healthy and fit when required to mate a large number of ewes. Dominant rams do much of the mating in peak estrus while subordinate males check out ewes early and late in estrus. 
Lambing occurs when a ewe has moved away from the flock. This allows exclusive attention to be given to the offspring and a good bond to be established. When ewe densities are high, lamb stealing or ewe interference can become common. This activity from other ewes usually occurs an hour or so before they lamb. This interference can have a disruptive effect on the lambing ewe and lead to increased lamb mortality especially in ewes with multiples. If the site set up for lambing is steep, lambs can slip and be lost. They may wander after other passing ewes (Kilgour et al. 1983a). A ewe should be undisturbed on the lambing site for four hours for good bonding onto single lambs and longer for twins or triplets (Alexander et al. 1983).

Eventually, sheep move away from the lambing site with their lambs following. Lambs suckle about once an hour and in association with the ewe learn much about the environment, the tracks, and good grazing areas. The whole tendency to flock arises from the early "following" patterns shown by lambs to ewes. Training "leader" sheep can assist the work on farms as sheep "follow" after leaders (Bremner et al. 1980). These are some of the essential and unique attributes of sheep as a species.

Some extrapolations to sheep welfare can be made: (a) Sheep should not be kept in isolation when they travel, are handled, or are slaughtered. A sheep without other companions has a raised heart rate and elevated blood stress hormone levels. It would take them several weeks to adjust to isolated conditions; (b) Shepherding at lambing may be a mixed blessing, especially if it interrupts the establishment of ewe-lamb bonds within a few hours of birth. Some of the benefits of "easy-care" lambing arise from the decrease in disruptive human interventions at lambing time; (c) It is legitimate to adopt husbandry practices which mimic the "ram effect" in the interests of good results at mating.

As a number of studies have been carried out on handling sheep and the measures of distress, it is helpful to focus on this aspect of the welfare of sheep. Kilgour and de Langen (1970) tied sheep up or monitored them as they went through various on-farm handling activities like dipping and shearing, and used blood plasma cortisols to assess their distress. Although the assay used was not a sophisticated one, later studies have borne out their contentions that sheep kept in groups are less distressed by handling than sheep in isolation. Later, Pearson et al. (1977) took serial blood samples from sheep leaving the farm and moving to slaughter to assess catecholamine and cortisol levels over the thirty-six hour period. Again, apart from lengthy water bath washing required by consumer hygiene requirements, the sheep were not unduly stressed until the actual time of stunning. With electrical stunning of the cortex, every physiological emergency process the animal has is switched on full, the catecholamines rise dramatically, reaching levels 
not shown in any other handling situations and cortisols also rise. But who can argue that "rendering an animal unconscious by the use of electric stunning before its blood is let" is, in fact, not in the animals' best welfare interests? What happens to a sheep in the hours after leaving the farm appears to me to be more important for its welfare then the precise mode of its final slaughter. Slaughter by whatever method takes no more than a minute at the end of a long process in which the transported sheep is washed, dried, and handled over a period of 24-36 hours. Each new hygiene regulation lengthens this stressful pre-slaughter process.

When considering methods of handling sheep without causing them undue distress, the excellent studies at the University of Melbourne (Hutson 1983) tested the principles of sheep handling first recorded by Mr. Hopkins.

Overall, fourteen handling principles have been investigated. Although more work was urgently required in this field, funding for this program was stopped, a tragic loss to sheep welfare studies.

Other Australian studies (Truscott and Wroth 1976) have examined the preparation of sheep for live export to the Persian Gulf ports. When troughs with pelleted feeds were offered to large flocks of sheep, some adjusted very quickly while a small group of "shy" feeders refused to feed. Once the new feed was accepted, most sheep adjusted very readily to shipboard environment although good ventilation is vital. Air extraction systems have been found to be the best. Feed and water containers which prevent spillage during rough seas have now been designed and are now in use.

Apart from the predator harrassment of sheep and the pain and suffering which results, there are few issues which relate to sheep welfare if they are run outdoors. Occasional droughts, or snowfalls can make proper care difficult. More information needs to be gathered by researchers about sheep reactions to housing, what the ideal site for lambing would be like, in what ways the best mating management can be practiced, what are the advantages and the disadvantages of high stocking rates with rotational grazing methods of management, and the relative pressures on twin and triplet lambs when raised by a ewe with only two teats.

\section{A Multi-Faceted Approach to Welfare}

Farmers can be given a short list of questions to help them assess the day by day animal welfare on their farms. However, farmers alone are not responsible for the changes in the humane treatment of animals which may need to occur. This is a total community responsibility, 
devolving especially on groups which decide welfare priorities and have a genuine concern for animals in our society. Five broad approaches to "welfare" issues have been suggested (Kilgour 1983).

1. We must use our knowledge of species' behavior and the distress associated with handling to identify areas of concern and change.

A much greater research effort needs to go into applied ethology or the scientific study of farm animal behavior. What is the current research effort in this field? Are groups which state they have an interest in farm animal welfare willing to fund research in this field to show their genuine interest? More complete ethograms or behavior inventories are needed for each of the farm species. Further studies of animal stress during the normal on-farm routines such as handling, milking, shearing, drenching, weighing, and transport are required. The most reliable indices of distress need further refinement so that there is some unanimity on this matter.

Once the behavior repertoire is documented to act as a baseline for husbandry decisions, there remains the problem of ranking the behavioral needs in sensible order. The need to eat sufficient food is rarely under debate except in decisions relating to backfat thickness in pigs or obesity in domestic dogs. Starving hens as a method of precipitating forced molt arouses a greater debate. Does the fact that pigs and deer wallow in outdoor mudholes make it a behavioral need to wallow? If wallowing is to regulate an animal's temperature, avoid flies, mark territory, or distribute pheromones, there might be no need for such behavior in a domesticated or intensively-housed deer or pig.

2. More care should be taken to pre-condition stock to the farming conditions, housing, transport, handling, etc., which they will experience.

There are a number of studies indicating that tender, gentle care (TGC) has an important place in enabling animals to adjust to farming conditions. Gross and Siegel (1983) have examined aspects of socialization of chickens in groups which are gentled, ignored, or hassled and indicated a relationship with feed conversion and their response to challenges from $E$. Coli infection and RBC antigens. Hemsworth et al. (1981) have assessed the reaction of sows to humans and shown a positive relationship with house productivity as measured by the number of piglets born. Seabrook (1972) has indicated the influence of milker/manager on dairy cow production. Overall, this field is little explored though the advantages of bonding during sensitive periods for pups (Scott et al. 1974) to humans has been utilized by some dog trainers. More knowledge is required of how early shaping and pre-conditioning will enable animals to fit their farming environments. 
3. Modifying aspects of the house, cage, feed or drinking unit to better suit the needs of the animals.

In 1969, McBride advised New Zealand poultry men to "fit their farms to fowl." In later research (McBride 1975), the floor area of a large deep-litter unit was restructured to see what changes in behavior would follow. Changes did occur and it was considered that the best quarters ended up like a rather poorly-designed tree. McBride (1976) concluded that a space could be cruel, comfortable, or boring and that attempting to define "cruelty" in terms of measurements of living quarters is not helpful. Tauson (1978) has taken "fitting farms to fowl" seriously. Some of his suggested changes for cages make them better quarters for laying hens.

While the search for more appropriate systems for laying hens continues, it seems wise and appropriate that the existing quarters be remodeled to fit the hen as best as is possible. There have been many reports of studies of cattle in stalls with a view to fitting stalls to cattle, but much more work needs to be undertaken in this area. Which research group has the responsibility of testing proposed engineering designs for new animal quarters or feeding dispensers to see if they in fact suit the animals for which they were designed?

\section{Search for strains or breeds better suited to current farming or intensive conditions.}

Heart rate studies of light and medium hybrid hens at the Poultry Research Centre in Edinburgh, Scotland, indicated that on presenting a standard "scaring object," the light hybrid, which appeared from behavior to be greatly stressed, in fact, had a rapid return of heart rate to normal. On the other hand, the medium hybrid, while appearing less concerned took much longer to adjust and maintained a high heart rate for much longer. Similarly, we have found in recent field observations on farmed red and fallow deer, that after handling, red deer take time to recover once they are returned to pasture. They appeared not unduly upset while being handled. The fallow get excited and disturbed during the handling process and injure themselves and their handlers, yet settle very quickly when returned to pasture.

Adequate objective criteria are needed together with appropriate tests to measure specific animal responses before any selection procedures can be carried out. The precise definition of the basic traits needed in the indoor or outdoor farm animals of the future is hard to clarify or forecast. In New Zealand, the move to select ewes which always produce twins has resulted in an increased proportion of triplets of lower birth weights and consequently high mortality rates.

If selection is to continue, all the available breed genetical materials must be retained. This is an important priority. The establishment of 
rare breed survival trusts is an encouraging sign and essential to future genetic programs of selection.

\section{Preventing disease and accidents}

Disease is considered by the Brambell Report (1965) to be the major source of animal pain and suffering. Programs of preventive health care are an essential requirement for the "humane care" of farm species. This is self-evident and prudent for the large intensive owner. Strict fire precautions, stand-by electricity plants, and early warning indicators of impending dangers such as increasing humidity or a buildup of ammonia are fundamental, and legislation and enforcement of such precautions are legitimate.

Automation, considered by some to be detrimental to the welfare of animals in intensive units, may not necessarily be so. The time saved together with reduced drudgery could free people for more man-animal interactions allowing better care. Many minor faults could be corrected before major breakdowns occur. Tender Gentle Care programs might become feasible with more automation. Automation could free more time to be given to training new stockpersons, take the pressure off existing workers, which in turn might reduce accidents and injury to humans and provide humane care for those who live and work with stock in large intensive farm units.

With this sort of multi-faceted approach, farmers, welfarists, and scientists could work together on the broad field of farm animal welfare for the ultimate benefit for the animals in the system. My concern is that this should be so.

\section{Acknowledgements}

I appreciate the constructive comments made by Drs. L.R. Matthews and D.C. Dalton after reading the original manuscript. 


\section{References}

Alexander, G., Stevens, D., Kilgour, R., de Langen, H., Mottershead, B.E. and Lynch, J.J. 1983. Separation of ewes from twin lambs: Incidence in several sheep breeds. Appl. Anim. Ethol. 10:301-17.

Brambell, F.W.R. 1965. Chairman. Report of the technical committee to inquire into the welfare of animals kept under intensive livestock husbandry systems. Command paper No. 2836 (HMSO: London) 96 pp.

Bremner, K.J., Braggins, J.B. and Kilgour, R. 1980. Training sheep as "leaders" in abattoirs and farm sheepyards. Proc. N.Z. Soc. Anim. Prod. 40:111-16.

Brownlee, A. 1950. Studies in the behaviour of domestic cows in Britain. Bull. Anim. Behav. 1(8):11-20.

Council for Agricultural Science Technology (CAST). 1981. Scientific aspects of the welfare of food animals. Report No. 91:1-54.

Gross, W.B. and Siegel, P.B. 1982. Socialization as a factor in resistance to infection, feed efficiency, and response to antigen in chickens. Amer. J. Vet. Res. 43(II):2010-12.

Hemsworth, P.H., Brand, A. and Willems, P. 1981. The behavioural response of sows to the presence of human beings and its relation to productivity. Livest. Prod. Sci. 8:67-74.

Hughes, B.O. 1976. Behaviour as an index of welfare. Proc. 5th European Poultry Conf. W.S.P.A. Malta. pp. 1005-18.

Hutson, G.D. 1983. Sheep behaviour project: A final report to the Australian Wool Corporation. University of Melbourne. $194 \mathrm{pp}$.

Kilgour, R. 1976. Sheep behaviour: its importance in farming systems, handling, transport and pre-slaughter treatment. In: Truscott, G.M.C. and Wroth, R.H. eds. Sheep Assembly and Transport Workshop. W. Aust. Dept. Agric. Publ. pp. 64-84.

Kilgour, R. 1978. The application of animal behavior and the humane care of farm animals. J. Anim. Sci. 46:1478-86.

Kilgour, R. 1980. Animal Welfare-the conflicting viewpoints. In: Wodzicka-Tomaszewska, M., Edey, T.N. and Lynch, J.J. eds. Behaviour in Relation to Reproduction, Management and Welfane of Farm Animals. Rev. in Rural Sci. IV. Armidale, N.S.W.: Univ. N.E. Press. pp. 175-82.

Kilgour, R. 1983. Stress and behaviour: an operational approach to animal welfare. In: Baxter, S.H., Baxter, M.R., and MacCormack, J.A.D., eds. Farm Animal Housing and Welfane. The Hague: C.E.C. Martinus Nijhoff Publ. pp. 36-44.

Kilgour, R. and Dalton, D.C. 1984. Livestock Behaviour-A Practical Guide. London: Collins Professional and Technical Books. $320 \mathrm{pp}$.

Kilgour, R. and de Langen, H. 1970. Stress in sheep resulting from management practices. Proc. N.Z. Soc. Anim. Prod. 30:65-76.

Kilgour, R. and Houston, J.B. 1979. Handling animals safely. N.Z. Fmr. 100(18):157-8.

Kilgour, R., Alexander, G. and Stevens, D. 1983. A field study of factors interrupting bonding of ewes and twins. In: Mantell, C.D. ed. Proc. 2nd Asia-Oceania Cong. Perinatology. pp. 118-23.

Kilgour, R., Matthews, L.R., Temple, W. and Foster, M. 1984. Using operant tests results for decisions on cattle welfare. In: Hall, W.F. ed. The Behavior and Welfane of Farm Animals. CENSHARE: Minnesota Uni. pp. 205-17.

Klopfer, F.D., Kilgour, R. and Matthews, L.R. 1981. Paired comparison analysis of palatabilities of twenty foods to dairy cows. Proc. N.Z. Soc. Anim. Prod. 41:242-47.

Knight, T.W. and Lynch, P.R. 1980. Source of ram pheromones that stimulate ovulation in the ewe. Anim. Reprod. Sci. 3(3):133-6.

Lindgren, N.O. 1976. The conflict between technical advances and ethics in animal production. Wld. Poult. Sci. J. 32:243-8.

Lynch, J.J., Mottershead, B.E. and Alexander, G. 1980. Sheltering behaviour and lamb mortality amongst shorn Merino ewes lambing in paddocks with restricted areas of shelter or no shelter. Appl. Anim. Ethol. 6:163-74. 
Martin, J.T. 1973. The role of the hypothalamic-pituitary-adrenal system in the development of imprinting and fear behaviour in wild and domesticated ducks. Thesis, Univ. Munchen, Germany.

McBride, G. 1969. Fitting farms to fowl. Proc. 4th Ann. Poult. Conv. Massey Uni., N.Z. pp. 1-9.

McBride, G. 1975. Behaviour and the design of the animal-husbandry interface. Proc. 3rd Comb. Conf. Aust. Chicken Meat Fed. Aust. Stockfd. Manufact. Assoc. Adelaide. pp. $91-95$.

McBride, G. 1976. Improving the welfare of livestock. Proc. 53rd Ann. Conf. Aust. Vet. Assoc. pp. 7-9.

Pearson, A.J., Kilgour, R., de Langen, H. and Payne, E. 1977. Hormonal responses of lambs to trucking, handling and electric stunning. Proc. N.Z. Soc. Anim. Prod. 37:243-8.

Scott, J.P., Stewart, J.M. and De Ghett, V.J. 1974. Critical periods in the organization of systems. Devlop. Psychobiol. 7:489-513.

Seabrook, M.F. 1972. A study to determine the influence of the herdsman's personality on milk yields. J. Agric. Labour Sci. 1:45-59.

Sossinka, R. 1982. Domestication in birds. In: Farmer, D.S., King, J.R. and Parkes, K.C. eds. Avian Biology, VA. London: Academic Press. pp. 383-404.

Spurway, H. 1955. The causes of domestication: An attempt to integrate some ideas of Konrad Lorenz with evolution theory. J. Genet. 53:325-62.

Squires, V.R. 1981. Livestock Management in the Arid Zone. Melbourne: Inkata Press. $271 \mathrm{pp}$.

Tauson, R. 1978. Cage design and welfare. Proc. 1st Danish Sem. Poult. Welfare in Egg-laying cages. pp. 63-77.

Truscott, G.M.C. and Wroth, F.H. 1976. Proc. Sheep Assembly and Transport Workshop. W. Aust. Dept. of Agric., Perth. 196 pp.

Wegner, R.M. 1983. Production performance in laying hens kept under different housing conditions. In: Smidt, D. ed. Indicators Relevant to Farm Animal Welfare. The Hague: Martinus Nijhoff. pp. 189-96. 